\title{
CFD analysis of an exceptional cyclist sprint position
}

\author{
Bert Blocken ${ }^{1,2}$ (D) Thijs van Druenen ${ }^{1} \cdot$ Yasin Toparlar ${ }^{1} \cdot$ Thomas Andrianne $^{3}$
}

Published online: 26 February 2019

(c) The Author(s) 2019

\begin{abstract}
A few riders have adopted a rather exceptional and more aerodynamic sprint position where the torso is held low and nearly horizontal and close to the handle bar to reduce the frontal area. The question arises how much aerodynamic benefit can be gained by such a position. This paper presents an aerodynamic analysis of both the regular and the low sprint position in comparison to three more common cycling positions. Computational fluid dynamics simulations are performed with the 3D RANS simulations and the transition SST $k-\omega$ model, validated with wind-tunnel measurements. The results are analyzed in terms of frontal area, drag coefficient, drag area, air speed and static pressure distribution, and static pressure coefficient and skin friction coefficient on the cyclist surfaces. It is shown that the drag area for the low sprint position is $24 \%$ lower than for the regular position, which renders the former $15 \%$ faster than the latter. This $24 \%$ improvement is not only the result of the $19 \%$ reduction in frontal area, but also caused by a reduction of $7 \%$ in drag coefficient due to the changed body position and the related changes in pressure distribution. Evidently, specific training is required to exert large power in the low sprint position.
\end{abstract}

Keywords Cycling position · Computational fluid dynamics · Numerical simulation · Wind tunnel $\cdot$ Aerodynamic cyclist drag $\cdot$ Cycling aerodynamics

\section{Introduction}

The greatest potential for improvement in cycling speed is situated in its aerodynamics [1]. At racing speeds (about $54 \mathrm{~km} / \mathrm{h}$ or $15 \mathrm{~m} / \mathrm{s}$ ), the aerodynamic resistance or drag is about $90 \%$ of the total resistance [2-4]. In sprints, however, higher speeds can be achieved, above $70 \mathrm{~km} / \mathrm{h}$. In general, professional cyclists use sprint positions that are focused on generating maximum power output, while less or no attention is given to aerodynamics (Fig. 1). These positions generally do not differ that much from each other and are mainly a function of rider and bicycle geometry. However,

Bert Blocken

b.j.e.blocken@tue.nl

1 Department of the Built Environment, Eindhoven University of Technology, P.O. Box 513, 5600 Eindhoven, The Netherlands

2 Department of Civil Engineering, KU Leuven, Kasteelpark Arenberg 40-Bus 2447, 3001 Leuven, Belgium

3 Department of Aerospace and Mechanical Engineering, University of Liège, Allée de la Découverte, 9 Quartier Polytech 1, B52/3, 4000 Liège, Belgium in the past years, a few riders have adopted a rather exceptional sprint position where the torso is held very low, nearly horizontal, and close to the handle bar to reduce the frontal area, as shown in Fig. 1 for one particular rider. While it is clear that specific training will be required to exert maximum power in such a position, the question arises how much aerodynamic benefit can be gained by such a position.

Aerodynamic drag in cycling can be assessed by field tests, wind-tunnel measurements, and numerical simulation by computational fluid dynamics (CFD). The use of CFD in sports aerodynamics in general, and in cycling in particular, has seen a rapid growth in the recent years (e.g., [5-15]). As opposed to field tests and wind-tunnel measurements, CFD allows whole flow-field data to be obtained under controlled conditions and is easily amenable to parametric analysis. Different CFD approaches can be applied to cycling aerodynamics, including large eddy simulation (LES) and Reynolds-averaged Navier-Stokes (RANS). While LES intrinsically has the potential to provide more accurate and more reliable results, this potential has not fully materialized due to the higher complexity and higher sensitivity of LES to the wide range of computational parameters to be set by the user and due to its much higher computational cost [16]. Indeed, 


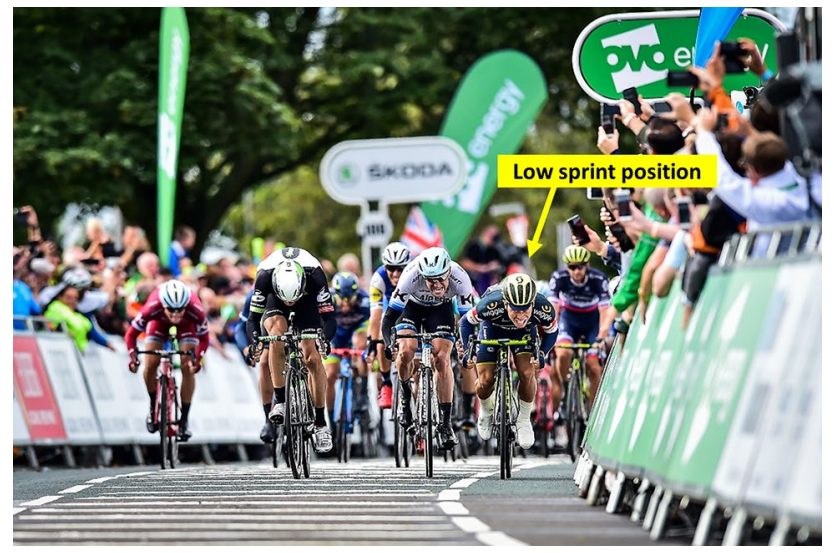

Fig. 1 Sprint positions including low sprint position adopted by cyclist Caleb Ewan. Source: (C) Arne Mill/frontalvision.com, reproduced with permission

most CFD simulations in cycling aerodynamics in the past were performed based on the RANS approach.

The previous CFD or wind-tunnel studies in cycling aerodynamics have focused on cyclists in different types of race or time trial positions, either isolated or followed by the other cyclists, motorcycles, or cars (e.g., [2-8, 12, 17-27]). Recent studies have also focused on paralympic tandem cycling [14, 28], paralympic handcycling [29], and even on full cyclist pelotons [9]. However, to the best of our knowledge, no previous study specifically focused on the aerodynamics of sprint positions.

This paper presents an aerodynamic analysis of both the regular and the low sprint position in comparison to three more common cycling positions. CFD simulations were performed with the 3D RANS simulations and the transition SST $k-\omega$ model, and validated with wind-tunnel measurements. The results are analyzed in terms of frontal area, drag coefficient, drag area, air speed and static pressure distribution, and static pressure coefficient and skin friction coefficient on the cyclist surfaces.

\section{Cyclist positions}

The focus was on the two sprint positions, as shown in Fig. 2a, b. However, for comparison purposes, three additional positions were added. The cyclist geometry was obtained by scanning a cyclist in dropped position using an Eva structured 3D light scanner [30]. The same athlete was used for all the scans to avoid anthropometric bias. Written consent of the scanned athlete was obtained, and the procedure of scanning, processing the body geometry, and reporting the results was approved by the ethical board committee. The athlete had a height of $1.83 \mathrm{~m}$ and a weight of a Position "Sprint regular"

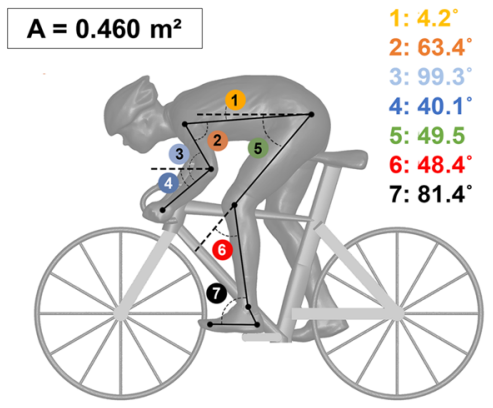

c Position "Back upwards"

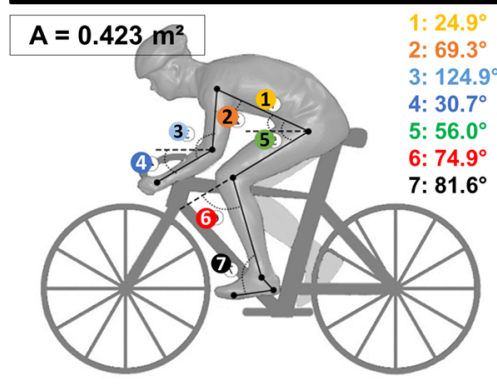

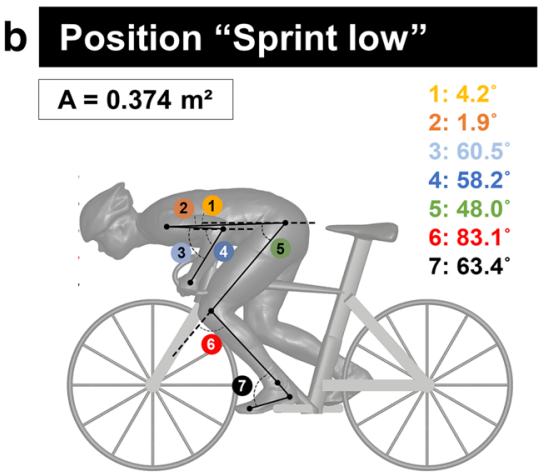

\section{Position "Back horizontal"}

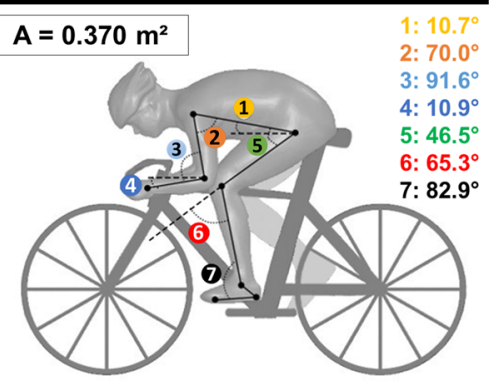

\begin{tabular}{|l|}
\hline 1: sagittal torso angle \\
2: shoulder angle \\
3: elbow angle \\
4: forearm angle \\
5: hip angle \\
6: knee angle \\
7: ankle angle
\end{tabular}

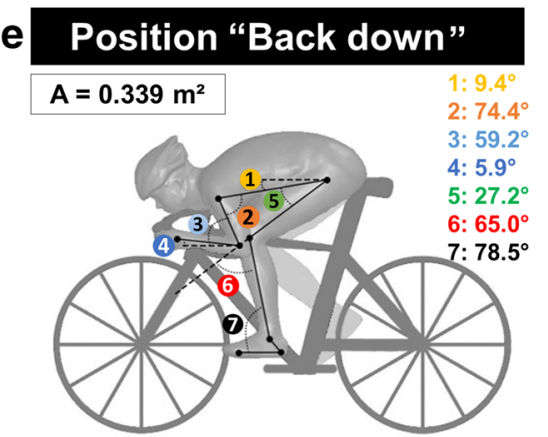

Fig. 2 The five cyclist positions with frontal area A and definition and values of (1) sagittal torso angle; (2) shoulder angle; (3) elbow angle; (4) forearm angle; (5) hip angle; (6) knee angle; (7) ankle angle 
$72 \mathrm{~kg}$. All five positions are depicted in Fig. 2, along with the frontal area A and seven characteristic angles specifying the position on the bicycle. Crank angles for all positions are about $5^{\circ}$, while, for "Sprint low", it is about $-5^{\circ}$. The legs of the cyclist were static and both wheels of the bicycle were fixed. The bicycle geometry was simplified, specifically concerning the front forks, wheel hubs and spokes, pedals, cranks, and handlebars. Some elements of the bicycle were neglected as they were considered small enough not to influence the characteristic flow around it. These included the chains, sprockets, and also brake and gear cables and mechanisms. The cyclist and bicycle surface were considered to be smooth (zero roughness). While it is clear that the power that can be exerted by the athlete will be different for each of these positions, these five positions were analyzed to provide a more extensive aerodynamic comparison.

\section{CFD simulations-part l: validation}

\subsection{Wind-tunnel measurements}

For two of the five cyclist positions, wind-tunnel experiments were conducted in the framework of a foregoing project and these were used for the validation study in the present paper: "Back horizontal" and "Back down" (Fig. 2d, e). The wind-tunnel measurements were performed in the aeronautical section of the wind tunnel at the University of Liège in Belgium. The cross section of the test section was $W \times H=2 \times 1.5 \mathrm{~m}^{2}$. A dedicated setup with an elevated sharp-edge horizontal plate and embedded force balance was developed and installed in the wind tunnel to limit boundary-layer development. The models were manufactured from ABS (acrylonitrile butadiene styrene) using CNC milling, resulting in smooth surfaces. To fully accommodate the models in the wind tunnel at a blockage ratio below 5\%, they were constructed at scale $1 / 4$, yielding a blockage ratio below $3.5 \%$. Tests were performed at $60 \mathrm{~m} / \mathrm{s}$ to ensure Reynolds number similarity with the (full scale) CFD simulations and with reality at $15 \mathrm{~m} / \mathrm{s}$ cycling speed. Drag in cycling is often quantified by the drag area $A C_{\mathrm{d}}\left(\mathrm{m}^{2}\right)$, which is the product of the frontal area of the cyclist $(A)$ and the drag coefficient $\left(C_{\mathrm{D}}\right)$. It relates the drag force $\left(F_{\mathrm{d}}\right)$ to the dynamic pressure $\left(\rho U_{\infty}^{2} / 2\right)$ :

$F_{\mathrm{d}}=A C_{\mathrm{d}} \frac{\rho U_{\infty}^{2}}{2}$,

where $\rho$ is the air density $\left(\mathrm{kg} / \mathrm{m}^{3}\right)$ and $U_{\infty}$ is the approachflow air speed $(\mathrm{m} / \mathrm{s})$. As no cross wind, head, or tail wind were considered, $U_{\infty}$ represented the cycling speed. The drag force, i.e., the horizontal component parallel to the wind direction and bicycle, was measured using a force transducer with a conservative maximum error estimate of $1.24 \mathrm{~N}$ with $95 \%$ confidence level, although the actual precision was expected to be much better [31]. Note that this error included both systematic and random errors, and that systematic errors were removed by biasing prior to every measurement. The data were sampled at $10 \mathrm{~Hz}$ for $180 \mathrm{~s}$. During the measurements, air temperature, speed, and atmospheric pressure were recorded to correct the measurements to the reference values of $15^{\circ} \mathrm{C}, 15 \mathrm{~m} / \mathrm{s}$, and $101,325 \mathrm{~Pa}$ as in the CFD simulations. The measurements were also corrected by subtracting the drag of the horizontal model support plate as well as for blockage using the expressions for solid blockage by Barlow et al. [32]. The boundary-layer height was $6 \mathrm{~cm}$, which was below the feet and pedals of the cyclist. The longitudinal turbulence intensity of the approach flow was lower than $0.2 \%$. The measurement results will be reported together with the CFD results in a later subsection.

\subsection{Computational geometry, domain, and grid}

CFD simulations were performed for the two positions tested in the wind tunnel. The full-scale cyclist and bicycle geometries were placed in a computational domain, the size of which was determined based on the best practice guidelines [33, 34], yielding $L \times W \times H=33.79 \times 16.49 \times 9$. $73 \mathrm{~m}^{3}$. The upstream, downstream, and lateral distances of the domain faces to the model were $7.94 \mathrm{~m}, 23.93 \mathrm{~m}$, and $7.95 \mathrm{~m}$, respectively. The maximum blockage ratio was $0.2 \%$, which was well below the recommended maximum value of $3 \%[33,34]$. The directional blockage ratios were below the maximum of $17 \%$ [34]. As a result, no blockage corrections were applied to the CFD simulations.

The grids were generated based on the grid generation best practice guidelines in CFD [33-36] and on specific guidelines for cycling aerodynamics as determined by extensive sensitivity analyses by Mannion et al. [14] and Blocken et al. [9]. These analyses pointed to the requirement for a wall-adjacent cell size of at least $20 \mu \mathrm{m}$ at the cyclist and bicycle surfaces and a prismatic boundary-layer mesh of 40 layers of incremental thickness with a maximum growth ratio of 1.1. These requirements were necessary to fully resolve the thin viscous/laminar sublayer and the buffer layer, and to correctly reproduce boundary-layer separation, reattachment, and laminar-to-turbulent transition. The dimensionless wall unit $y^{*}$ was generally lower than 1 . Outside the 40 layers, tetrahedral and/or prismatic cells were used. Figure 3 illustrates the grids for the two positions on the cyclist and bicycle surfaces and in the vertical centerplane. 
Fig. 3 Computational grids for the two positions on the cyclist and bicycle surfaces and in the vertical centerplane. Total cell counts: a 37,744,105; b $37,748,609$

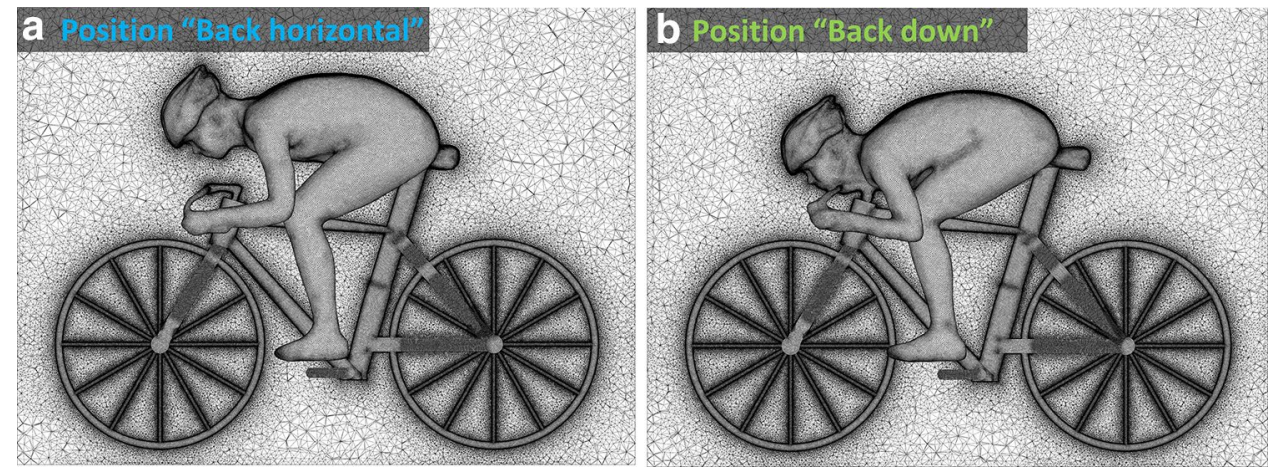

\subsection{Boundary conditions}

At the inlet, a uniform $15 \mathrm{~m} / \mathrm{s}$ velocity was set with a turbulence intensity of $0.2 \%$, representative of the relative air movement due to cycling at this speed in still air (zero wind speed). It was assumed that the cyclist was riding on a flat and straight road. The cyclist and bicycle surfaces were modeled as smooth no-slip walls corresponding to the smooth surface finish of the wind-tunnel models. A slip wall was imposed at the bottom boundary of the domain and symmetry conditions at the side and top boundaries of the domain. At the outlet, zero static gauge pressure was imposed.

\subsection{Approximate form of governing equations and solver settings}

The 3D RANS equations were solved with the Langtry-Menter 4-equation transition shear stress transport (SST) $k-\omega$ model $[37,38]$, which is based on coupling the SST $k-\omega$ transport equations with two additional transport equations, one for the intermittency and one for the transition onset criteria, in terms of momentum thickness and Reynolds number. This model was applied here with inclusion of curvature correction and with production limiters [39]. Pressure-velocity coupling was taken care with the coupled scheme, pressure interpolation was second order, and the second-order discretization schemes were used for both the convection terms and the viscous terms of the governing equations. A second-order discretization scheme was also applied for the four turbulence model equations. The gradients were computed with the Green-Gauss cell-based method [39]. The simulations were performed with the commercial CFD code ANSYS Fluent, release 16. The pseudo-transient under-relaxation method was employed with 6000 time steps of $0.01 \mathrm{~s}$. Results were obtained by averaging over the last 5000 pseudo-transient time steps.

\subsection{Results}

The CFD results are compared with the wind-tunnel results in terms of drag area in Fig. 4. For the "Back down" position, the deviation between CFD and wind-tunnel measurements was $2.2 \%$ and within the error range of the measurements. For the "Back horizontal" position, however, the deviation was $7.2 \%$ and outside the measurement error range. The reason for the latter and larger deviation is not fully clear. It is possible that the separation points/lines on the surface of this particular model were located at

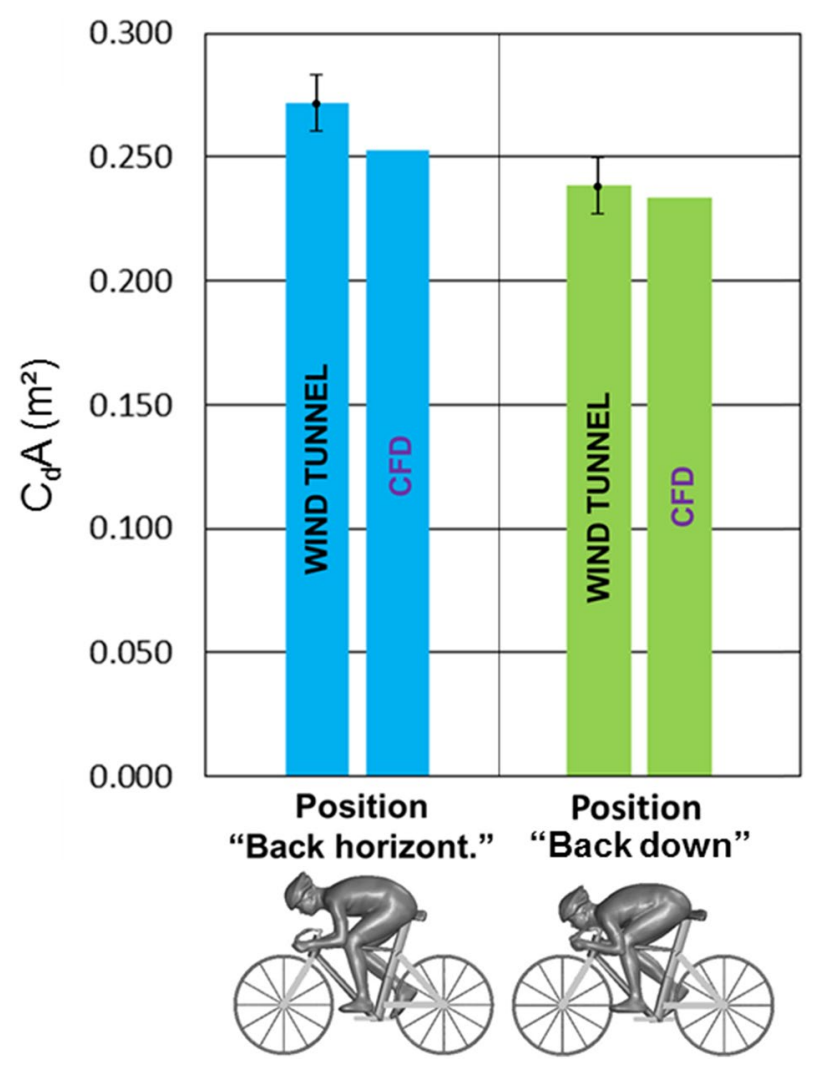

Fig. 4 Comparison of wind-tunnel and CFD results for the two tested models in terms of drag area 
positions where the resulting drag is more sensitive to a small shift in these positions, and, hence, more difficult to reproduce computationally. Nevertheless, the magnitude of the drag area was predicted fairly well for both positions $(<10 \%$ deviation) as well as the decreasing trend from position "Back horizontal" to "Back down", and, therefore, the same computational parameters and settings were retained for the parametric study in the next section. Note that the CFD simulations were performed for an approachflow wind speed of $15 \mathrm{~m} / \mathrm{s}$ and that the wind-tunnel measurements were performed for an approach-flow wind speed at $60 \mathrm{~m} / \mathrm{s}$ at reduced scale (quarter scale), corresponding to $15 \mathrm{~m} / \mathrm{s}$ at full scale. Sprint speeds, however, will generally be significantly higher. CFD simulations for the two different cyclist positions were also performed for $20 \mathrm{~m} / \mathrm{s}$ $(72 \mathrm{~km} / \mathrm{h})$ and $25 \mathrm{~m} / \mathrm{s}(90 \mathrm{~km} / \mathrm{h})$ which yielded nearly the same drag areas for every position (deviations below $0.5 \%$ ).

\section{CFD simulations-part Il: parametric analysis}

\subsection{Computational geometry, settings, and parameters}

In total, CFD simulations were performed for five different positions, i.e., the two sprint positions ("Regular" and
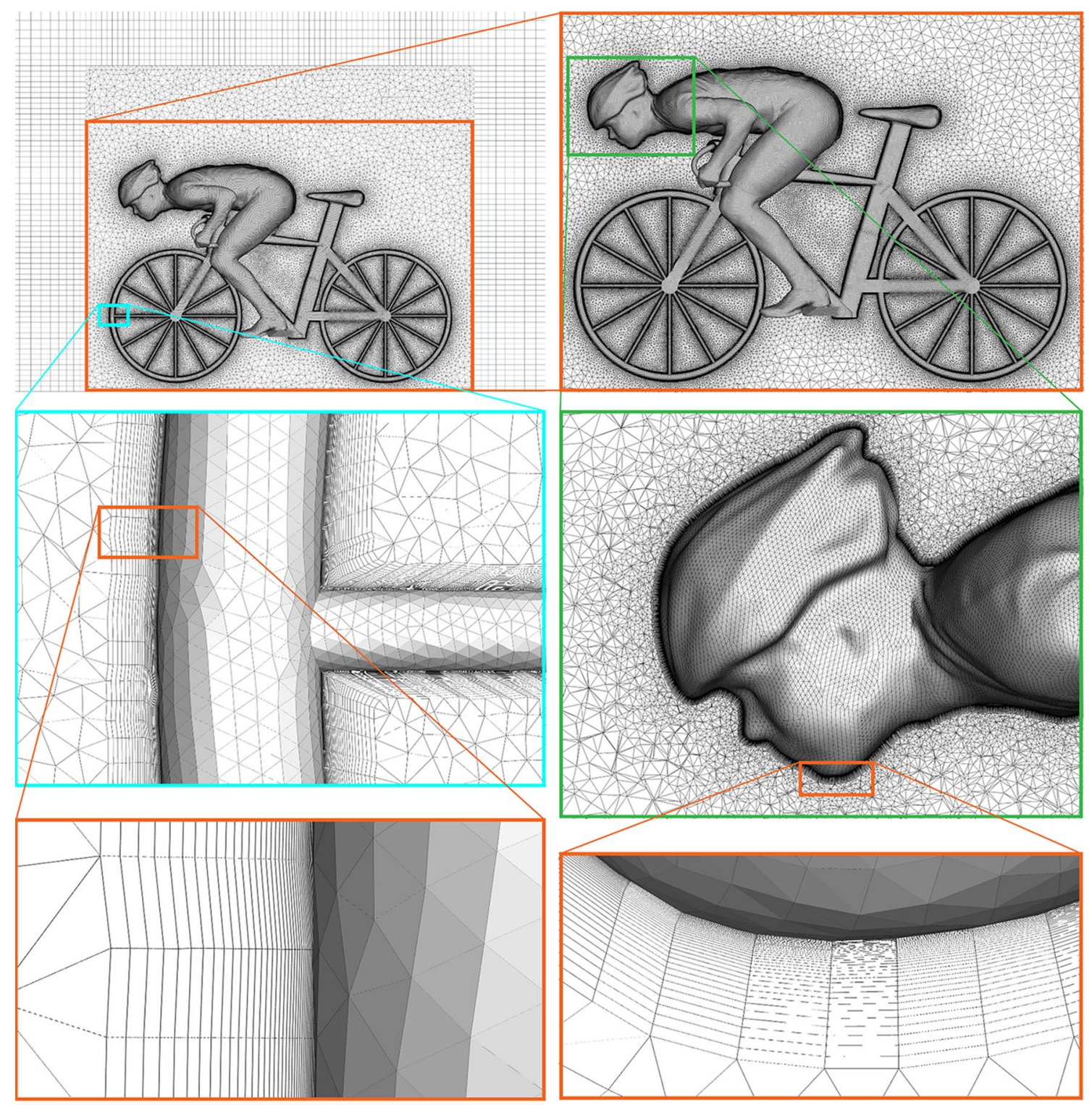

Fig. 5 Details of computational grid on cyclist and bicycle surfaces and in the vertical centerplane. Wall-adjacent cell size is $20 \mu \mathrm{m}$; 40 layers of prismatic cells are used in the boundary layer. Cell count: $30,019,706$ 
"Low"), the two positions of the validation study and the position "Back up" (Fig. 2). The simulations were performed at full scale. The computational domain had a size according to best practice guidelines [33, 34]: $L \times W \times H$ $=33.79 \times 16.49 \times 9.73 \mathrm{~m}^{3}$. The upstream, downstream, and lateral distances of the domain faces to the model were identical to those in Sect. 3.2. The maximum blockage ratio was $0.2 \%$, which is well below the threshold of $3 \%$ $[33,34]$. The directional blockage ratios were below the threshold value of $17 \%$ [40]. Given these low blockage ratios, the CFD simulations were not corrected for blockage. The grids were similar to those outlined in Sect. 3.2. The total cell counts were approximately $28 \times 10^{6}$, $30 \times 10^{6}, 31 \times 10^{6}, 38 \times 10^{6}$, and $38 \times 10^{6}$ for "Sprint regular", "Sprint low", "Back upwards", "Back horizontal", and "Back down", respectively. Figure 5 shows grid details for the position "Sprint low", including the high-resolution near-wall grid with cell sizes down to $20 \mu \mathrm{m}$ and the 40 prismatic grid layers. The solver settings (approximate form of the governing equations, turbulence model, boundary conditions, discretization schemes, etc) were identical to those in Sect. 3.4. It was again assumed that there was no cross wind, head, or tail wind, and that the cyclist was riding on a flat and straight road.

\subsection{Results and discussion: drag coefficient, drag area, and speed}

Figure 6 compares the frontal area, the drag coefficient, and the drag area for the five positions. The numerical values are listed in Table 1. The frontal area is largest for the "Sprint regular" position, and smallest for the "Back down" position. Compared to the "Sprint regular" position, the "Sprint low" position has a 19\% lower frontal area. However, the frontal areas of the "Back horizontal" and "Back down" positions are even lower, $20 \%$ and $26 \%$, respectively, compared to the "Sprint regular" position. However, these are not really sprint positions. The drag coefficient is also largest for the "Sprint regular" position, followed by the "Back up" and "Back down" position, and smallest for the "Sprint low" position. Compared to the "Sprint regular" position, the "Sprint low" positions had a 7\% lower drag coefficient. Finally, the product of frontal area and drag coefficient yields the drag area. The drag area was highest for the "Sprint regular" position and lowest for the "Back down position". Compared to the "Sprint regular" position, the drag area of the "Sprint low" position was $24 \%$ lower, and that of the "Back down" position was $28 \%$ lower. The lower drag area for the "Sprint low" position was not only caused by the lower frontal area, but also by the lower drag coefficient.

The drag area reduction for the "Sprint low" position compared to the "Sprint regular" position can be translated into a speed increase for the former compared to the latter position. If we assume that the cyclist exerts the same power in both positions and that all resistive forces are identical in both positions,

Table 1 Frontal area, drag coefficient, and drag area for the five cyclist positions

\begin{tabular}{llll}
\hline Position & $A\left(\mathrm{~m}^{2}\right)$ & $C_{\mathrm{d}}(-)$ & $C_{\mathrm{d}} A\left(\mathrm{~m}^{2}\right)$ \\
\hline Sprint regular & 0.460 & 0.670 & 0.308 \\
Sprint low & 0.374 & 0.626 & 0.234 \\
Back up & 0.423 & 0.655 & 0.277 \\
Back horizontal & 0.370 & 0.638 & 0.236 \\
Back down & 0.339 & 0.655 & 0.222 \\
\hline
\end{tabular}

Fig. 6 Frontal area $A$, drag coefficient $C_{\mathrm{d}}$, and drag area $C_{\mathrm{d}} A$ for the five positions

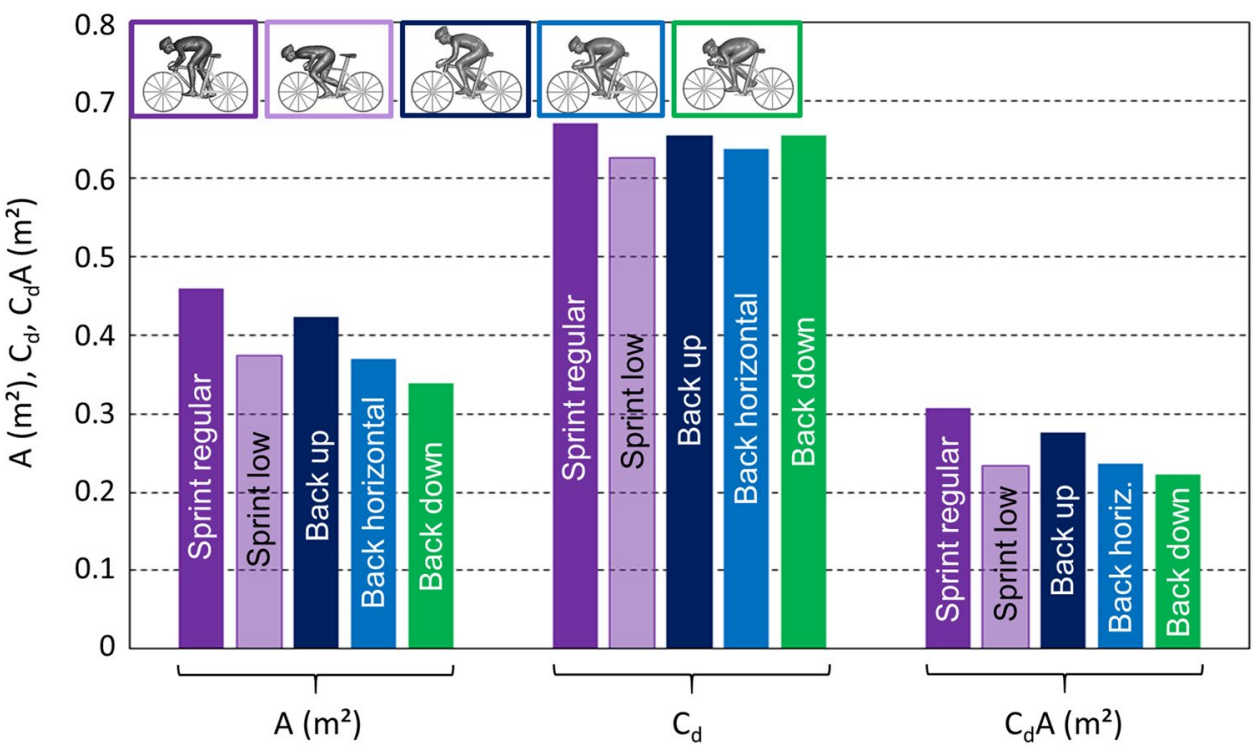


the drag forces in both positions will be identical, as well, and Eq. (1) can be applied to yield:

$\frac{U_{1}}{U_{2}}=\sqrt{\frac{\left(C_{\mathrm{d}} A\right)_{2}}{\left(C_{\mathrm{d}} A\right)_{1}}}$,

where $U_{1}$ and $U_{2}$ are the cycling speeds in positions 1 (sprint low) and 2 (sprint regular), respectively, and $\left(C_{\mathrm{d}} A\right)_{1}$ and $\left(C_{\mathrm{d}} A\right)_{2}$ are the drag areas in positions 1 and 2, respectively. Application of Eq. (2) for $\left(C_{\mathrm{d}} A\right)_{1}=0.234 \mathrm{~m}^{2}$ and $\left(C_{\mathrm{d}} A\right)_{2}=0.308 \mathrm{~m}^{2}$ yields $U_{1}=1.147 U_{2}$, indicating that the cycling speed in position "Sprint low" is about $15 \%$ higher than in position "Sprint regular", on condition that the same power is exerted in both positions.

\subsection{Results and discussion: mean air speed and mean static pressure coefficient}

Figure 7 displays the contours of mean air speed and mean static pressure coefficient in the vertical centerplane. The static pressure coefficient is defined as follows:

$C_{P}=2 \frac{P-P_{0}}{\rho U_{\infty}^{2}}$

where $P$ is the mean static pressure and $P_{0}$ the reference static pressure (=atmospheric pressure). Note that the $C_{\mathrm{p}}$ colorbar was cut at -0.5 and +0.5 to better highlight the pressure gradients. The lower position in Fig. $7 \mathrm{~b}$ clearly leads to a less high wake and a lesser disturbance of the flow. In addition, because the torso is at the same height of the saddle, the saddle is in the wake of the torso and not exposed to strong wind as in Fig. 7a. Figure 7c shows that the low-pressure area above the cyclist is more pronounced and that there is a separate low-pressure area behind the saddle, which generates an additional resistance force, while, in Fig. 7d, pressure gradients around the saddle are more limited. Although the contours provide a first indication of the aerodynamic performance of the two positions, more information can be gained from the mean pressure coefficient and the mean skin friction coefficient on the cyclist and bicycle surfaces.

\subsection{Results and discussion: mean surface pressure coefficient and mean surface skin friction coefficient}

Figure 8 displays the mean surface pressure coefficient and Fig. 9 shows the mean surface skin friction coefficient. In general, the surface pressure coefficient is the highest at the areas of direct flow impingement and stagnation, i.e., the front part of the helmet, arms and legs. It is lowest directly downstream of the separation lines, i.e., the shoulders, the sides of the arms, legs, and the back of the lower torso. However, the separation and recirculation area on the shoulders, arms, legs, and back of lower torso extends further downstream than indicated by the dark blue color in Fig. 8. The larger extent of this area is shown by the mean surface skin friction coefficient in Fig. 9. Indeed, the lowest $C_{\mathrm{f}}$ values
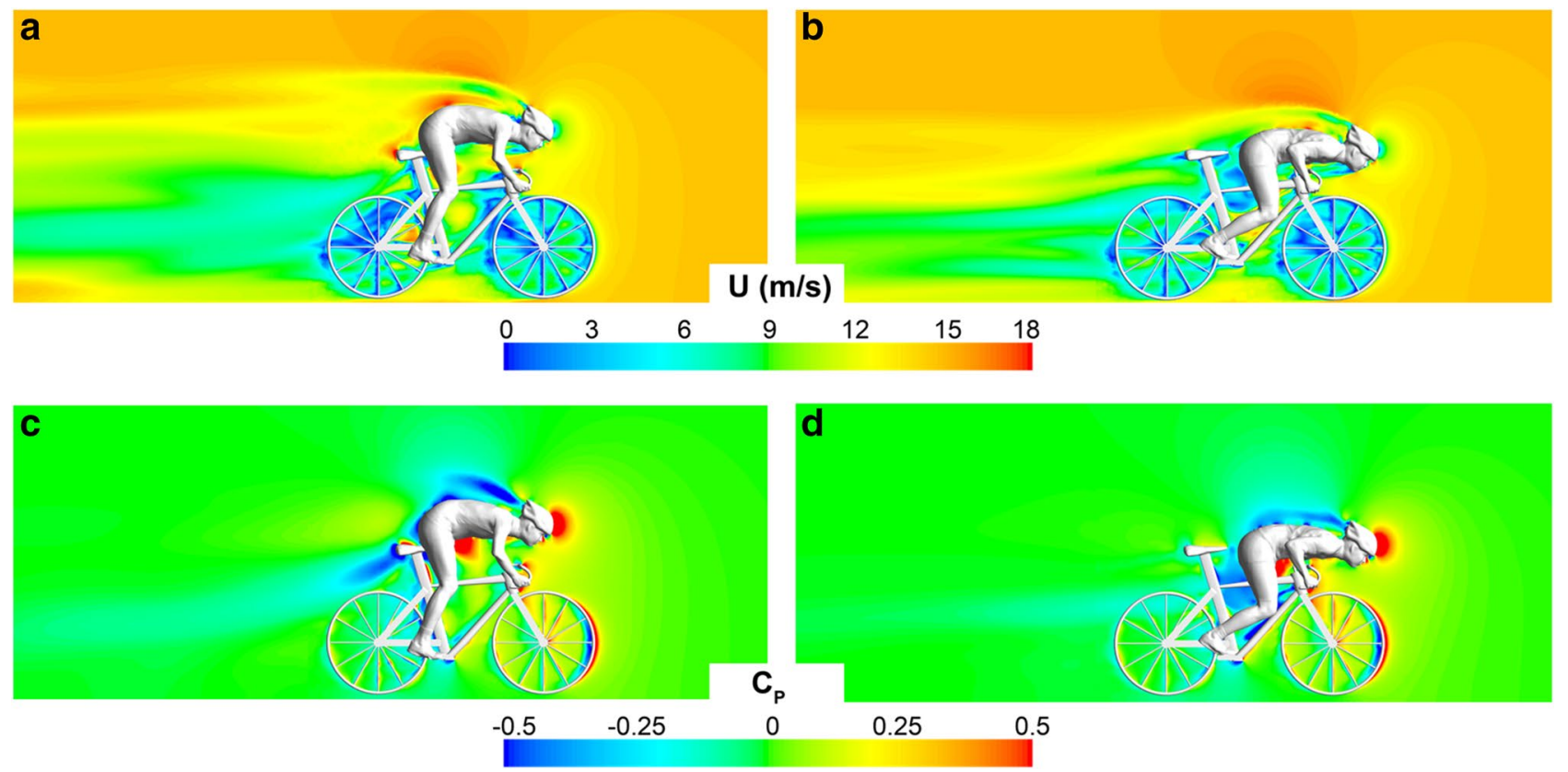

Fig. 7 Contours of $\mathbf{a}, \mathbf{b}$ mean air speed and $\mathbf{c}, \mathbf{d}$ mean static pressure coefficient in a vertical centerplane for the two sprint positions. (Color figure online) 
Fig. 8 Contours of mean static pressure coefficient on cyclist and bicycle surfaces for the two sprint positions. (Color figure online) a
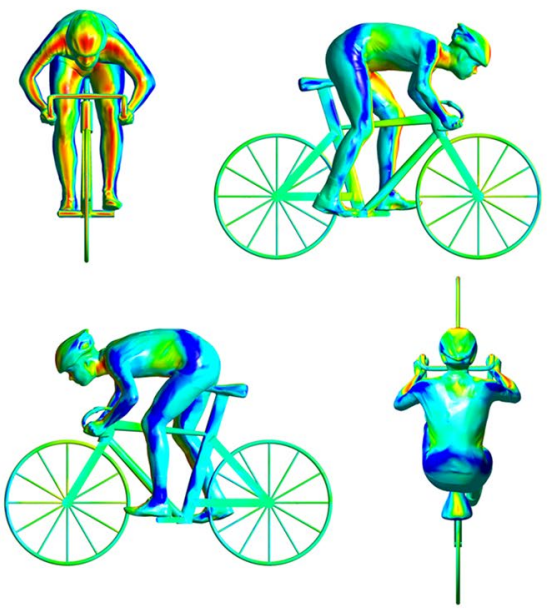

b
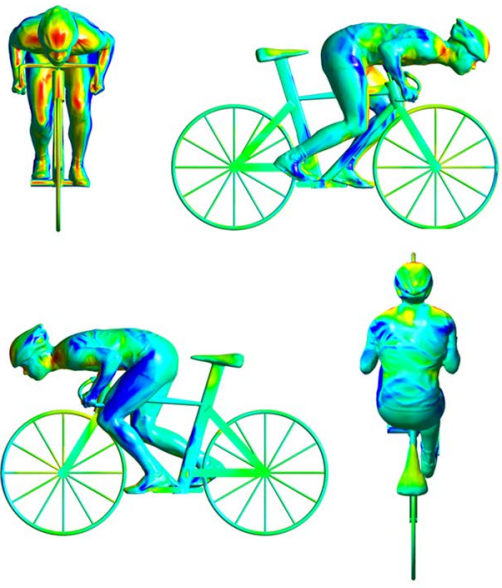

a
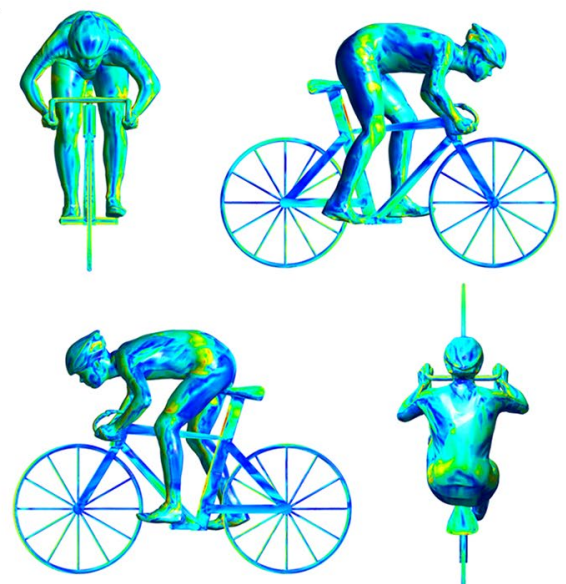

friction coefficient on cyclist and bicycle surfaces for the two sprint positions. (Color figure online)
$\mathrm{C}_{\mathrm{p}}$

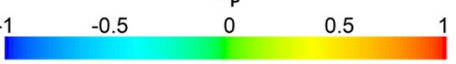

b

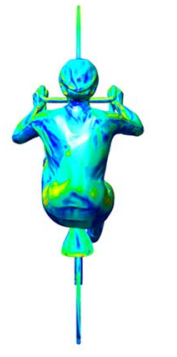

0 0.007

$\mathrm{C}_{\mathrm{f}}$
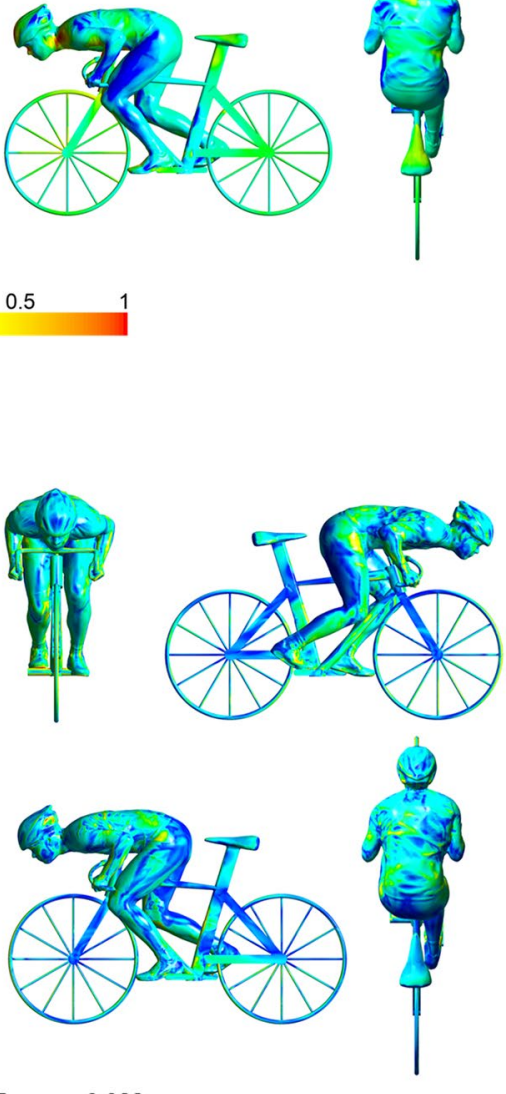

are found near the end of the separation bubble and these indicate positions where the recirculating flow impinges and a stagnation point develops from which the flow diverges. Low $C_{\mathrm{f}}$ is also found at the upwind stagnation zones, i.e., at the front part of the helmet, shoulders, upper arms, and legs.

Comparing both sprint positions in Fig. 8, it is clear that the areas of high pressure on the front of the body were more pronounced for the "Sprint regular" position. Due to the inclination of the upper arms and lower legs, high pressure at these positions was less pronounced for the "Sprint low" position. In terms of low-pressure areas, the low pressure at the lower back of the cyclist was less pronounced for the "Sprint low" position. Concerning the bicycle, the different exposure of the saddle also contributed to the difference between the two positions. These aspects result in a $C_{\mathrm{d}}$ that is $7 \%$ lower for the "Sprint low" position compared to the "Sprint regular" position.
For bodies of relatively simple geometry, changes in the mean skin friction coefficient can indicate where the boundary layer undergoes a transition from laminar over transitional to turbulent. However, for more complicated bodies and the resulting complex flows with streamline curvature, separation, recirculation, and reattachment, as in cycling aerodynamics, it is difficult to extract such information. On the other hand, $C_{\mathrm{f}}$ values can help to indicate the extent of separation and recirculation areas and positions of reattachment. Moreover, the contribution of skin friction to the overall drag is low. For the "Sprint regular" position, the drag consists of $97.1 \%$ form drag (related to $C_{\mathrm{p}}$ ) and $2.9 \%$ skin friction drag (related to $C_{\mathrm{f}}$ ). For the "Sprint low" position, these percentages are $95.8 \%$ and $4.2 \%$ for form and skin friction drag, respectively. Note, however, that zero surface roughness was adopted in the CFD simulations and, 
therefore, actual values for skin friction drag contributions are expected to be somewhat higher.

\section{Limitations and further work}

Although this study was based on high-resolution and validated CFD simulations applied for different cyclist positions, there are also some limitations related to the choice of cyclist model. The cyclist positions were all based on the scans of the same person with given body characteristics. This was done to allow a comparison between the different positions and to remove anthropometric bias. Although the values of the frontal area, drag coefficient, and drag area will differ for different athletes, it is expected that the trends found in the present study will be similar for different athletes, although the precise numbers will undoubtedly vary. It is expected that the largest deviations from the present study will occur for cyclists that are at the extremes of the anthropometric spectrum, i.e., very tall or very short athletes, or athletes with very large or small leg/torso ratio. Although the athlete in the "Sprint low" position in Fig. 1 (Caleb Ewan) is considered to be rather at one of the extremes of the anthropometric spectrum, the athlete in our study, who is clearly not at this extreme given his height and weight, did not have much difficulty in assuming the "Sprint low" position. Nevertheless, future research should focus on the aerodynamic performance of sprinting positions by athletes with different anthropometric characteristics.

The CFD simulations and the wind-tunnel measurements in the present paper had static legs and the wheels were fixed. During a sprint, a high pedaling frequency is achieved. Earlier research has shown that the aerodynamic drag of a pedaling cyclist, averaged over one pedaling revolution, is similar to that of the same cyclist with the crank almost horizontal [41]. Nevertheless, the high pedaling frequency is expected to have an influence on the resulting drag areas, although this influence could be expected to be similar for the "Sprint regular" and "Sprint low" positions if the pedaling frequency is the same in both positions. In addition, during a sprint, the torso generally undergoes lateral movements, which were also not included in the present study. An indication of the effect of rotating wheels was provided by Blocken et al. [9] where it was shown that, for the cyclist in "Back up" position, the CFD simulation for the static wheels yielded a drag force of $36.06 \mathrm{~N}$, while the simulation for the same geometry with rotating wheels yielded $37.30 \mathrm{~N}$. This small difference would indicate that wheel rotation is not a major factor in the aerodynamic drag of an isolated cyclist, at least in the absence of cross wind.

All CFD simulations and wind-tunnel measurements in this study assumed that the cyclist(s) was/were riding in still air, so no head wind, tail wind, or cross wind is present.
Future research should investigate, especially, the effect of cross wind on the drag area of different cyclist sprint positions.

Other simplifications in this study included the steadystate calculations (in spite of the pseudo-transient approach) and the assumption that the cyclist surfaces were smooth; so no special skinsuits with roughness texture were included. The use of such skinsuits can further reduce the drag areas.

Figure 3 indicates that the mesh resolution in the wake is fairly coarse. Even though this resolution resulted from grid sensitivity studies in the previous publications that included several different cyclist positions [9, 42, 43], further research is needed to determine how near-wake grid resolution affects the computed drag and surface pressure distributions for sprint positions.

This study did not consider potential differences in power that can be exerted by cyclists in different positions. It is evident that exerting maximum power in the "Sprint low" position is less straightforward than in the "Sprint regular" position, and that the former will, therefore, require much more dedicated training. In the past, investigations concerning the relation between cyclist drag and power output were performed by Grappe et al. [44], Underwood et al. [45], and Fintelman et al. [46-48]. Future studies should definitely address the effects of different cyclist sprint positions on power and on optimizing aerodynamic drag and power output.

\section{Conclusions}

Computational fluid dynamics (CFD) simulations were performed to assess the aerodynamic benefit that can be gained by adopting a sprint position where the torso is held low and nearly horizontal and close to the handle bar with the main intention to reduce the frontal area. The results were analyzed in terms of frontal area, drag coefficient, drag area, air speed and static pressure distribution, and static pressure coefficient and skin friction coefficient on the cyclist surfaces. It was shown that the drag area for the low sprint position was $24 \%$ lower than for the regular position, which rendered the former $15 \%$ faster than the latter. This $24 \%$ improvement was the combined result of a $19 \%$ reduction in frontal area and a $7 \%$ reduction in drag coefficient. The reduction in drag coefficient was related to changes in the distribution of the mean pressure coefficient.

In the regular sprint position, the areas of high pressure on the front part of the body were clearly more pronounced. Due to the inclination of the upper arms and lower legs, high pressure at these positions was less pronounced for the "Sprint low" position. The contours of $C_{\mathrm{p}}$ and $C_{\mathrm{f}}$ were used to highlight the location and the extent of separation and recirculation areas. The upstream part of these areas was 
indicated by low $C_{\mathrm{p}}$, while the downstream part was indicated by low $C_{\mathrm{f}}$. These areas are important, because they are characterized by low pressure (suction). It was shown that the low pressure at the lower back of the cyclist was less pronounced for the "Sprint low" position, leading to lower $C_{\mathrm{d}}$.

Evidently, specific training is required to exert large power in the low sprint position. Future research should focus on analyzing sprint positions by athletes with different anthropometric characteristics, including pedaling and including cross wind effects, and on the maximum power that can be exerted in particular positions.

Acknowledgements The authors would like to thank the technical support team of the Department of the Built Environment at Eindhoven University of Technology, Ing. Jan Diepens, Geert-Jan Maas, and Stan van Asten for preparing and setting up the wind-tunnel experiments in the wind-tunnel laboratory in Liège. The authors also acknowledge the partnership with ANSYS CFD. This work was also sponsored by NWO Exacte en Natuurwetenschappen (Physical Sciences) for the use of supercomputer facilities, with the financial support from the Nederlandse Organisatie voor Wetenschappelijk Onderzoek (Netherlands Organization for Scientific Research, NWO).

Open Access This article is distributed under the terms of the Creative Commons Attribution 4.0 International License (http://creativeco mmons.org/licenses/by/4.0/), which permits unrestricted use, distribution, and reproduction in any medium, provided you give appropriate credit to the original author(s) and the source, provide a link to the Creative Commons license, and indicate if changes were made.

\section{References}

1. Wilson DG (2004) Bicycling science, 3rd edn. MIT Press, Cambridge

2. Kyle CR, Burke ER (1984) Improving the racing bicycle. Mech Eng 106(9):34-45

3. Grappe G, Candau R, Belli A, Rouillon JD (1997) Aerodynamic drag in field cycling with special reference to the Obree's position. Ergonomics 40(12):1299-1311

4. Lukes RA, Chin SB, Haake SJ (2005) The understanding and development of cycling aerodynamics. Sports Eng 8:59-74

5. Hanna RK (2002) Can CFD make a performance difference in sport? In: Ujihashi S, Haake SJ (eds) The engineering of sport 4. Blackwell Science, Oxford, pp 17-30

6. Defraeye T, Blocken B, Koninckx E, Hespel P, Carmeliet J (2010) Aerodynamic study of different cyclist positions: CFD analysis and full-scale wind-tunnel tests. J Biomech 43(7):1262-1268

7. Defraeye T, Blocken B, Koninckx E, Hespel P, Verboven P, Nicolai B, Carmeliet J (2014) Cyclist drag in team pursuit: influence of cyclist sequence, stature, and arm spacing. J Biomech Eng ASME 136(1):011005

8. Blocken B, Defraeye T, Koninckx E, Carmeliet J, Hespel P (2013) CFD simulations of the aerodynamic drag of two drafting cyclists. Comput Fluids 71:435-445

9. Blocken B, van Druenen T, Toparlar Y, Malizia F, Mannion P, Andrianne T, Marchal T, Maas GJ, Diepens J (2018) Aerodynamic drag in cycling pelotons: new insights by CFD simulation and wind tunnel testing. J Wind Eng Ind Aerodyn 179:319-337

10. Blocken B (2014) 50 years of computational wind engineering: past, present and future. J Wind Eng Ind Aerodyn 129:69-102
11. Griffith MD, Crouch T, Thompson MC, Burton D, Sheridan J, Brown NAT (2014) Computational fluid dynamics study of the effect of leg position on cyclist aerodynamic drag. ASME J Fluids Eng 136(10): 101105

12. Fintelman DM, Hemida H, Sterling M, Li FX (2015) CFD simulations of the flow around a cyclist subjected to crosswinds. J Wind Eng Aerodyn 144:31-41

13. Crouch TN, Burton D, LaBry ZA, Blair KB (2017) Riding against the wind: a review of competition cycling aerodynamics. Sports Eng 20(2):81-110

14. Mannion P, Toparlar Y, Blocken B, Hajdukiewicz M, Andrianne T, Clifford E (2018) Improving CFD prediction of drag on paralympic tandem athletes: influence of grid resolution and turbulence model. Sports Eng 21(2):123-135

15. Beaumont F, Taiar R, Polidori G, Trenchard H, Grappe F (2018) Aerodynamic study of time-trial helmets in cycling racing using CFD analysis. J Biomech 67:1-8

16. Blocken B (2018) LES over RANS in building simulation for outdoor and indoor applications: a foregone conclusion? Build Simul. https://doi.org/10.1007/s12273-018-0459-3

17. Dal Monte A, Leonardi LM, Menchinelli C, Marini C (1987) A new bicycle design based on biomechanics and advanced technology. Int J Sport Biomech 3:287-292

18. Zdravkovich MM, Ashcroft MW, Chisholm SJ, Hicks N (1996) Effect of cyclist's posture and vicinity of another cyclist on aerodynamic drag. In: Haake $\mathrm{S}$ (ed) The engineering of sport. Balkema, Rotterdam, pp 21-28

19. Jeukendrup AE, Martin J (2001) Improving cycling performance: how should we spend our time and money. Sports Med 31(7):559-569

20. Defraeye T, Blocken B, Koninckx E, Hespel P, Carmeliet J (2010) Computational fluid dynamics analysis of cyclist aerodynamics: performance of different turbulence-modelling and boundary-layer modelling approaches. J Biomech 43(12):2281-2287

21. Defraeye T, Blocken B, Koninckx E, Hespel P, Carmeliet J (2011) Computational fluid dynamics analysis of drag and convective heat transfer of individual body segments for different cyclist positions. J Biomech 44(9):1695-1701

22. Crouch TN, Burton D, Brown NAT, Thomson MC, Sheridan J (2014) Flow topology in the wake of a cylist and its effect on aerodynamic drag. J Fluid Mech 748:5-35

23. Blocken B, Toparlar Y (2015) A following car influences cyclist drag: CFD simulations and wind tunnel measurements. J Wind Eng Ind Aerodyn 145:178-186

24. Fintelman DM, Sterling M, Hemida H, Li FX (2014) The effect of crosswinds on cyclists: an experimental study. Eng Sport 10 Procedia Eng 72:720-725

25. Barry N, Burton D, Sheridan J, Thompson M, Brown NAT (2015) Aerodynamic drag interactions between cyclists in a team pursuit. Sports Eng 18(2):93-103

26. Barry N, Burton D, Sheridan J, Thompson M, Brown NAT (2016) Flow field interactions between two tandem cyclists. Exp Fluids 57(12):181

27. Blocken B, Toparlar Y, Andrianne T (2016) Aerodynamic benefit for a cyclist by a following motorcycle. J Wind Eng Ind Aerodyn 155:1-10

28. Mannion P, Toparlar Y, Blocken B, Clifford E, Andrianne T, Hajdukiewicz M (2018) Aerodynamic drag in competitive tandem para-cycling: road race versus time-trial positions. J Wind Eng Ind Aerodyn 179:92-101

29. Mannion P, Toparlar Y, Blocken B, Clifford E, Andrianne T, Hajdukiewicz M (2018) Analysis of crosswind aerodynamics for competitive handcycling. J Wind Eng Ind Aerodyn 180:182-190

30. Artec Europe (2017) Artec Eva, 3D scanners. https://www.artec 3d.com/3d-scanner/artec-eva. Accessed 22 May 2017 
31. Gore M (2016) Personal communication with sensor manufacturer

32. Barlow JB, Rae WH, Pope A (1999) Low-speed wind tunnel testing, 3rd edn. Wiley, New York

33. Franke J, Hellsten A, Schlünzen H, Carissimo B (2007) Best practice guideline for the CFD simulation of flows in the urban environment, COST Action 732: quality assurance and improvement of microscale meteorological models, Hamburg, Germany

34. Tominaga Y, Mochida A, Yoshie R, Kataoka H, Nozu T, Yoshikawa M, Shirasawa T (2008) AIJ guidelines for practical applications of CFD to pedestrian wind environment around buildings. J Wind Eng Ind Aerodyn 96(10-11):1749-1761

35. Casey M, Wintergerste T (2000) Best practice guidelines. ERCOFTAC special interest group on "quality and trust in industrial CFD", ERCOFTAC

36. Tucker PG, Mosquera A (2001) NAFEMS introduction to grid and mesh generation for CFD. In: Wilson DG (ed) NAFEMS CFD working group, R0079, 2004. Bicycling science, 3rd edn. MIT Press, Cambridge

37. Menter FR, Langtry R, Volker S (2006) Transition modelling for general purpose CFD codes. Flow Turbul Combust 77(1):277-303

38. Langtry RB, Menter FR (2009) Correlation-based transition modeling for unstructured parallelized computational fluid dynamics codes. AIAA J 47(12):2894-2906

39. ANSYS Fluent (2013) Release 15.0, theory guide. ANSYS Inc, Canonsburg

40. Blocken B (2015) Computational fluid dynamics for urban physics: Importance, scales, possibilities, limitations and ten tips and tricks towards accurate and reliable simulations. Build Environ 91:219-245
41. Crouch TN, Burton D, Thompson MC, Brown NAT, Sheridan J (2016) Dynamic leg-motion and its effect on the aerodynamic performance of cyclists. J Fluids Struct 65:121-137

42. Blocken B, van Druenen T, Toparlar Y, Andrianne T (2018) Aerodynamic analysis of different cyclist hill descent positions. J Wind Eng Ind Aerodyn 181:27-45

43. Blocken B, Toparlar Y, van Druenen T, Andrianne T (2018) Aerodynamic drag in cycling team time trials. J Wind Eng Ind Aerodyn 182:128-145

44. Grappe F, Candau R, Busso T, Rouillon JD (1998) Effect of cycling position on ventilator and metabolic variables. Int J Sports Med 19:336-341

45. Underwood L, Schumacher J, Burette-Pommay J, Jermy M (2011) Aerodynamic drag and biomechanical power of a track cyclist as a function of shoulder and torso angles. Sports Eng 14(2-4):147154. https://doi.org/10.1007/s12283-011-0078-z

46. Fintelman DM, Sterling M, Hemida H, Li FX (2014) Optimal cycling time trial position models: aerodynamics versus power output and metabolic energy. J Biomech 47(8):1894-1898

47. Fintelman DM, Hemida H, Sterling M, Li FX (2015) The effect of time trial cycling position on physiological and aerodynamic variables. J Sports Sci 33(16):1730-1737

48. Fintelman DM, Sterling M, Hemida H, Li FX (2016) Effect of different aerodynamic time trial cycling positions on muscle activation and crank torque. Scand J Med Sci Sports 26(5):528-534

Publisher's Note Springer Nature remains neutral with regard to jurisdictional claims in published maps and institutional affiliations. 